\author{
Students' Conceptions of Reflection: \\ Opportunities for Making Connections with Perpendicular Bisector \\ Anna F. DeJarnette \\ University of Cincinnati \\ Gloriana González, Jason T. Deal, and Sahid L. Rosado Lausell \\ University of Illinois at Urbana-Champaign
}

Author Note

Anna F. DeJarnette, Department of Curriculum and Instruction, University of Cincinnati.

Gloriana González, Jason T. Deal, and Sahid L. Rosado Lausell, Department of Curriculum and Instruction, University of Illinois at Urbana-Champaign.

This study was partially funded by the National Science Foundation's grant to Gloriana González for the project entitled “CAREER: Noticing and Using Students' Prior Knowledge in Problem-Based Instruction," Grant No. DRL-1253081. Opinions, findings, conclusions, or recommendations are those of the authors and do not necessarily reflect the views of the National Science Foundation. The authors acknowledge valuable feedback from George Francis on the design of the problem.

Correspondence concerning this article should be addressed to Gloriana González, Department of Curriculum and Instruction, University of Illinois at Urbana-Champaign, Champaign, IL, 61820.

Email: ggonzlz@illinois.edu 


\begin{abstract}
Given the current emphasis on the use of transformations for the teaching and learning of geometry, there is opportunity to consider how students' understanding of geometric transformations can be used to build connections with interrelated concepts. We designed a sequence of three problems, collectively referred to as "the pottery lesson," to elicit evidence of students' understanding of reflections. We asked: What conceptions of reflection did students use while working on the pottery lesson? How did students' work on a sequence of problems requiring reflecting create opportunities for establishing connections between reflections and perpendicular bisector? We identified opportunities for the use of perpendicular bisector to shift between an operation of students' work and a measure of control. The characterization of students' conceptions of reflection, and students' related use of perpendicular bisector, provide a resource for the teaching of these concepts to build upon students' prior knowledge to promote learning.
\end{abstract}




\section{Students' Conceptions of Reflection:}

Opportunities for Making Connections with Perpendicular Bisector

In the United States, the Common Core State Standards for Mathematics (NGAC, 2010) place a renewed emphasis on the use of geometric transformations for establishing relationships between geometric objects (NGAC, 2010). In particular, students should have opportunities to develop a definition of a reflection as a transformation using perpendicular lines and segments (NGAC, 2010, p. 76). With the opportunity to revisit the use of transformations in geometry classes, it is necessary to know how to leverage students' prior knowledge of reflections for the purpose of making its connection with perpendicular bisector explicit. Prior research has documented the different ways that students reflect figures (Mhlolo \& Schäfer, 2014), discuss reflective symmetry (Healy \& Hoyles, 1997), and prove conjectures related to reflections (Miyakawa, 2004). We seek to expand research on students' understanding of reflections by examining how students' work on problems about reflecting provides opportunities for a teacher to establish connections with the perpendicular bisector. This work considers how teachers can use the emphasis on transformations in geometry to build connections with interrelated objects and relationships.

We are interested in the question, how do students' conceptions of reflective symmetry either highlight or obscure connections with perpendicular bisector? We designed a sequence of problems to elicit students' prior knowledge of reflections and to provoke the use of perpendicular bisector in relation to reflections. Through an investigation of students' work, we propose how an instructional sequence may build upon students' initial conceptions to promote students' ability to apply perpendicular bisector in relation to reflections. With our overarching 
question, we seek to contribute to a broader investigation of how teachers can use students' prior knowledge to establish connections between mathematical ideas.

\section{Research Questions}

We examined students' work on a sequence of problems collectively referred to as "the pottery lesson," asking two research questions: (a) What conceptions of reflection did students use to complete the pottery lesson? (b) How did students' work on a sequence of problems requiring reflecting create opportunities for establishing connections between reflections and perpendicular bisector? We used students' work on the pottery lesson to consider how instruction can leverage students' prior knowledge to foster connections between perpendicular bisector and reflective symmetry.

\section{Conceptual Framework}

We based our analysis on the $\mathrm{cK} \varnothing$ (pronounced "c-k-c") model of students' conceptions (Balacheff, 2013; Balacheff \& Gaudin, 2002, 2010). The cK $\varnothing$ model, which stands for conception-knowing-concept, makes a distinction between mathematical concepts and the different conceptions that students may have about a single concept. The cK $\varnothing$ model of conceptions uses a definition of a mathematical concept as "a set of situations, a set of operational invariants (contained in schemes), and a set of linguistic and symbolic representations" that give meaning to a particular idea (Vergnaud, 2009, p. 94). The concept of reflection, for example, encompasses multiple problem situations, such as a problem about constructing a reflection or a problem about proving that a reflection satisfies certain properties. We also consider here that the concept of reflection, which emphasizes the use of a transformation, can be considered distinct from the concept of reflective symmetry, which 
emphasizes a property of a single figure. ${ }^{1}$ Because different types of problems elicit different uses of a concept, the definition of concept is meant to encompass all of those different uses, including different actions and representations one might use to solve the problems.

The term students' conceptions has been used in the past to refer generally to students' explanations of mathematical concepts, students' beliefs, "naïve theory," or "the mathematics of the child" (Confrey, 1990). Students may have multiple ways of using a concept such as reflection to solve problems in mathematics. A reflection, as a geometric transformation, specifies a relationship between two points or figures. The process of reflecting refers to the activity involved in producing such a relationship. There are multiple ways that students may solve problems about creating or describing reflections, for example through the use of drawings, geometric constructions, or measurements. Given these differences, it is conceivable that students have multiple conceptions of reflection, which brings to light the importance of characterizing these different conceptions. The $\mathrm{cK} \phi$ model operationalizes the construct of a conception to allow for examination of students' understanding of a concept through their work in a particular context.

\section{The Role of a Problem in a Conception}

The $\mathrm{cK} \phi$ model of students' conceptions builds upon the theory of conceptual fields (Vergnaud, 1981, 2009) and the theory of didactical situations (Brousseau, 1997), which provide a background for understanding how mathematics problems become part of the ways that students think about mathematics. We use the term learner to refer to a student who is engaging with a particular mathematics concept (Balacheff, 2013; Brousseau, 1997). The milieu is the

\footnotetext{
${ }^{1}$ Reflection and reflective symmetry can, however, be considered elements of a single conceptual field, which describes a collection of interrelated concepts and problem situations (Vergnaud, 2009).
} 
subset of the learner's environment that is relevant for learning that particular concept. For the purpose of studying students' conceptions, we consider students as learners in relation to the knowledge, representations, tools, and questions relating to some geometric concept. The milieu can be thought of as the learner's "antagonist system" to provoke the learning process (Brousseau, 1997, p. 57). Learners interact with the milieu by posing questions and developing and implementing strategies to solve problems with the resources available. The milieu provides feedback to the student. For example, given a pre-image and a line of reflection drawn on a piece of paper, a student might reflect the pre-image by folding the paper along the given line and tracing. The student uses aspects of the milieu — namely drawing upon the knowledge of what a reflection looks like, folding the paper, and tracing the image - to determine whether she or he has drawn the reflection correctly. The student gets feedback from the milieu in the form of whether the resulting figure looks like a reflection, or whether the pre-image and image align across the line of reflection.

A mathematical conception emerges through the interaction between the learner and the milieu. A problem is a perturbation in the learner-milieu interaction, which the learner must resolve (Balacheff, 2013). For example, suppose a student is asked to create a figure with reflective symmetry. The student would not have the option of using a given line of reflection and tracing a given figure, a method that may have previously worked on another problem. The student might first draw a line of reflection and then construct points equidistant from that line of reflection. Alternatively, the student could draw a collection of points on paper, fold the paper, and trace to create a single image with reflective symmetry. In this way, problems can be thought of as the source of a learner's understanding of a particular concept (Vergnaud, 1981). Problems contribute to the generation of different conceptions, because problems call for 
different ways of applying related concepts. The ways that a student solves a problem and gets feedback from the milieu contributes to the student's conception.

\section{The cKø Model for Studying Mathematical Conceptions}

The cKф model (Balacheff, 2013; Balacheff \& Gaudin, 2002, 2010) provides a way to describe conceptions by taking into account the interactions between students and the milieu. A conception $\mathrm{C}$ is defined as a quadruplet $C=(P, R, L, \Sigma)$ in which

- $\quad P$ refers to a set of problems that require particular use of a concept;

- $\quad R$ refers to a set of operations, the actions a learner performs to interact with the milieu;

- $\quad L$ refers to a system of representations and semiotic resources that represent the problem and allow the learner to access the milieu;

- $\quad \Sigma$ is a control structure, which validates the use of certain operations and representations to solve a particular problem.

The triplet of problems, operations, and representations are analogous to Vergnaud's (1981, 1998, 2009) definition of concept, emphasizing the interaction of the learner with the milieu. The set of operations includes mathematical operations, in addition to actions such as drawing a diagram, constructing a geometric figure, or folding a piece of paper. The semiotic resources can include conversation, symbolic language, geometric diagrams, or body language such as pointing or gesturing (Balacheff, 2013; Balacheff \& Gaudin, 2010). In sum, the semiotic resources include the media through which the problem is described and the learner performs operations.

The control structure accounts for students' metacognitive behaviors as they solve problems (Balacheff, 2013). The control structure of a conception highlights the importance of self-monitoring for students' problem-solving processes (Schoenfeld, 1985). Specifically, as students resolve perturbations in the learner-milieu interaction, they use a variety of means to 
assess whether their operations and use of representations are correct. For example, students who consider an infinite series as a sequence of partial sums know that techniques for summing finite series (e.g., commuting and re-associating terms) are not valid for infinite series (MartínezPlanell, Gonzalez, A. C., DiCristina, \& Acevedo, 2012). A measure of control can be a crucial element for students to determine the validity of a particular action for solving a problem.

The control structures of students' conceptions are sometimes evident through students' observable behaviors. For example, a student who draws a reflection may physically fold a piece of paper to check whether the pre-image and image align across a line of reflection. The example of paper folding illustrates an important feature of the conceptions framework, that an action serving as an operation of one conception may serve the role of a control structure in other conception (González \& Herbst, 2009). Students often rely on previously learned ideas or personal judgments to serve as control structures, such as using the definition of reflection to determine that the operation of constructing a reflected point is correct (Balacheff, 2013). In these cases, it can be difficult to observe the control structures students use in their conceptions. When students work together in groups and talk about their solutions, they can provoke one another to make the rationale behind their decisions explicit.

Our rationale for using the $\mathrm{cK} \phi$ model in this study is that the model gives balanced focus to the learner and the milieu. The way a problem is presented and interpreted by students-for example whether the problem begins with an already-constructed diagram - has implications for the conceptions students use to solve it (e.g., González \& Herbst, 2009; Herbst, 2005). Additionally, distinct problems that surface in different settings can elicit different conceptions of a single concept. For example, students may use different conceptions of reflection for proving than they do for constructing figures (Miyakawa, 2004). There have been efforts in 
mathematics education research to design problems that will provoke learners to develop increasingly sophisticated conceptions (e.g., Herbst, 2005) or that will challenge learners' initial conceptions (Páez Murillo \& Vivier, 2013). We are interested in how students' work on a sequence of distinct but related problems can support connections between interrelated concepts, in the particular case of reflections and perpendicular bisector. To accomplish this work, the $\mathrm{cK} \phi$ model is instrumental for examining the interactions between students, problems, and the conceptions that surface.

\section{Students' Conceptions of Perpendicular Bisector and Reflective Symmetry}

We review literature related to students' use of perpendicular bisector in problem solving and proving, as well as literature on students' thinking about reflections and reflective symmetry, in light of the $\mathrm{cK} \not$ model of students' conceptions.

\section{Students' Use of Perpendicular Bisector for Proving and Problem Solving}

There are examples in mathematics education research of how students draw or construct perpendicular bisectors as an operation towards justifying mathematical relationships. For example, two pairs of high school students constructed perpendicular bisectors in a dynamic geometry environment to determine the conditions under which the perpendicular bisectors of a quadrilateral would intersect at a single point (Marrades \& Gutiérrez, 2000). Neither pair used the properties of perpendicular bisector to prove their conjectures. When examining triangles, students might measure, construct, or approximate the placement of a perpendicular bisector to help locate the center of the triangle (Herbst, 2005). In tasks where students need to formulate or justify conjectures about mathematical relationships, creating a perpendicular bisector may be a useful operation. However, this does not imply that students use the perpendicular bisector as a semiotic resource or as a control structure to validate claims in a proof. 
In addition to making conjectures about mathematical relationships, students also use perpendicular bisector when creating geometric models of real-world phenomena. For example, a typical geometry problem may require students to divide a polygonal region into three subregions by identifying a point equidistant from the existing vertices (e.g., Perham \& Perham, 2011; Poehl, 2012; Zbiek \& Connor, 2006). In a problem about locating a new hospital to be shared by three cities, many prospective teachers identified the need to locate the hospital in the middle of the triangle formed by the three cities (Zbiek \& Connor, 2006). Although students proposed the use of a perpendicular bisector, some instead drew the altitudes of the triangle. When students incorrectly perform the operation of creating a perpendicular bisector, the perpendicular bisector is of little use as a semiotic resource for other mathematical purposes such as locating the center of a triangle, or describing the relationship between a point and its reflection.

\section{Students' Thinking About Reflections and Reflective Symmetry}

Because a line of reflection is the perpendicular bisector of a segment connecting a point and its reflection, research on students' thinking about reflections can illuminate some of the connections between the two concepts. In early grades, students are likely to think of reflective symmetry as a static property of a single figure, for example focusing on shapes such as squares that exhibit reflective symmetry ( $\mathrm{Ng} \&$ Sinclair, 2015). Over time, students can begin to describe the functional relationship between a pre-image and an image over a line of reflection. This shift, from reflective symmetry as a property to reflection as a transformation, indicates that students begin to develop a set of operations through which they can create a reflection. In a study with middle-grades students, many of the students' strategies for reflecting objects resulted in images that required some combination of reflections, rotations, and translations to produce 
(Hoyles \& Healy, 1997). Students at this stage did not use the knowledge that a point and its reflection would be equidistant from the line of reflection as a measure of control. Without this control structure, students performed operations that did not always produce reflected figures. Depending on the semiotic resources provided in a task - particularly whether the given line of reflection was vertical, horizontal, or diagonal—students performed different operations to produce the image.

Students in later grades also vary in how they integrate perpendicular bisector into their understanding of reflections. Through use of dynamic geometry, Hollebrands (2003) found that students were able to explain that a line of reflection would be the perpendicular bisector of the segment connecting a point and its reflection. This knowledge served as a control structure for students to identify pre-images and images related by a reflection. Other research suggests that, when given a collection of points to reflect, secondary students may instead connect the points, indicating that students view reflective symmetry as a property of a single figure but do not see reflection as a transformation of a single point (Mhlolo \& Schäfer, 2014). Students who view reflective symmetry only as a visual property are not likely to use perpendicular bisector for the purpose of reflecting, while students who define a reflection through its relation to perpendicular bisector can use that definition to identify reflections among other transformations.

Students who have studied perpendicular bisector in relation to reflections invoke different conceptions for different types of problems. For example, Miyakawa (2004) examined the work of 25 students solving a pair of problems — one about constructing and one about proving. In the construction problem, students needed to reflect a line segment $A B$ over a given line of reflection $d$ (Figure 1a). All but one pair of students used the property that $d$ would be the perpendicular bisector of $A A^{\prime}$ and, respectively, $B B^{\prime}$ as a control structure to motivate their 
actions. The second problem asked students to prove whether or not opposite sides $A D$ and $B C$ of a rectangle were symmetric across a line $M N$ connecting the midpoints of $A B$ and $C D$ (Figure 1b). Many students who produced a correct construction to solve the first problem did not produce a correct proof for the second problem, even though both problems required the same knowledge of the perpendicular bisector. Even tasks drawing upon the same mathematical relationships may elicit different conceptions from learners based upon how they are posed.

\begin{tabular}{|l|l|l|}
\hline & Figure 1b. Proving the rectangle is symmetric. \\
\hline Figure la. Reflecting a segment over a line. & Fig \\
\hline
\end{tabular}

Figure 1. Figures representing two problems about reflective symmetry (Miyakawa, 2004).

Finally, teachers make instructional decisions in response to student work that have the potential to shape students' use of reflections and perpendicular bisector. Son and Sinclair (2010) conducted interviews with a group of pre-service teachers (PSTs) to examine how they would evaluate and respond to a student's error on a problem of reflecting a flag across a diagonal line. Over half of the PSTs in the study evaluated the student's work according to the properties of reflection in relation to the perpendicular bisector. In doing so, the PSTs evaluated students' use of particular control structure for validating the reflection. However, when asked for their pedagogical strategies to respond to the student, many PSTs did not attend to the properties of reflection but instead proposed operations they would perform with the student, such as paper folding and flipping. The authors posited that the PSTs' focus on operations in this 
scenario, particularly paper folding and flipping, could potentially be productive strategies for establishing a conceptual understanding of reflection. These strategies highlight the close link between the operations of paper folding and flipping, and the relationship between a pre-image, its image, and the line of symmetry.

Overall, the research reviewed suggests that students often perform operations to construct perpendicular bisectors, but students are less proficient in using perpendicular bisector as a semiotic resource in solving geometric problems. Moreover, students often do not draw upon the properties of perpendicular bisector as a measure of control, particularly when solving problems related to reflections and reflective symmetry. We seek to contribute to the literature by considering how students' learning can be facilitated in such a way as to promote flexible use of perpendicular bisector through the performance of operations, their use of semiotic resources, and as a measure of control when solving a sequence of problems about reflections.

\section{Data and Methods}

The data for this study come from a project of investigating students' conceptions in geometry. We conducted a sequence of focus group sessions with high school geometry students to examine how students use knowledge of school mathematics, informal mathematical practices, and contextual information to solve problems (DeJarnette \& González, 2016a, 2016b; DeJarnette, Rosado Lausell, \& González, 2015; González, DeJarnette, \& Deal, 2014).

\section{Setting of the Study}

The session that was the focus of this study took place after school at the beginning of the 2nd semester in a high-need school in a Midwestern town in the United States. The school is ethnically diverse, with $60 \%$ low-income students. We recruited participants by advertising the 
project in the geometry classes of one of the teachers at the school. The geometry teacher ${ }^{2}$ was teaching both honors geometry and the regular geometry course at the school. We gave participants a cash stipend.

\section{The Design of the Pottery Lesson}

At the time of the study, students had previously studied geometric transformations, as well as perpendicular bisector, in their geometry classes. The pottery lesson included a sequence of three tasks in the context of recreating reflective patterns on pieces of pottery. Students needed to create patterns that they could imagine wrapping around circular pieces of pottery such as jars or bowls. We chose to design a sequence of problems within the context of pottery because an overarching goal of the project was to embed students' study of reflection within a realistic context, as in the approach of Realistic Mathematics Education (Freudenthal, 1991). Even though students had prior knowledge of perpendicular bisector, we did not know whether students would remember that concept or whether they would see it as relevant to the pottery lesson. We did not give students specific instructions on how they should solve the problems in the pottery lesson, because we wanted to investigate how students' solutions could create opportunities for making connections between interrelated concepts. We expected that students would use a variety of methods for solving the sequence of problems. The first author acted as the teacher for the session, and students worked on the lesson for a total of 55 minutes. The teacher offered students tracing paper, rulers, and compasses for students to use if they wanted.

Our purpose in designing the lesson was to elicit students' initial conceptions of reflection, and then to provoke students to make explicit use of the perpendicular bisector, in

${ }^{2}$ From here on, we use the term "geometry teacher" to refer to students' geometry teacher at the school. We use the term "teacher" to refer to the first author, who acted as the teacher for the pottery lesson. 
three consecutive parts. In part I of the pottery lesson, students were given half of a symmetrical leaf design and had to complete the second half (Figure 2a). Then, they had to make a strip pattern of six completed figures. The instructions on the handout required students to "finish the design" in a way that would create a pattern with reflective symmetry. The instructions did not specify how students should reflect the figure. Based upon our a priori analysis of the task, we identified two important characteristics in part I of the lesson: the half-leaf figure gave students the opportunity to produce a single figure with internal symmetry through the act of reflecting, and it also suggested a vertical line of symmetry. Based upon students' prior knowledge of leaves, which typically have bilateral symmetry, and research suggesting students have many informal experiences with reflective symmetry (Sinclair, Pimm, \& Skelin, 2014), we expected that the figure in part I of the lesson would provide an entry point for students' work. In the language of the $\mathrm{cK} \varnothing$ model, students' informal experiences with reflection could serve as a control structure to motivate their operations for creating a reflection. Even without knowledge of perpendicular bisector, students could use an operation of drawing to reflect the half leaf.

\begin{tabular}{|l|l|}
\hline & \\
\hline
\end{tabular}


Figure 2. The diagrams provided with the three parts of the pottery lesson.

In part II, students were given a figure and asked to use reflective symmetry to make a pattern of six of the figures (Figure 2b). The handout asked students to "describe the step-bystep process" for making a pattern with reflective symmetry. Part II differed from part I of the lesson in two important ways. First, the figure we provided to students contained no internal symmetry, and students were not instructed to produce a single figure with internal symmetry. Second, the figure in part II did not imply a line of reflection like the vertical line in part I had. Our goal with this part of the lesson was to initiate a shift in students' operations, in particular that they would determine a line of reflection external to the given figure. Whereas students could use visual perception of reflective symmetry as a control structure in part I, we expected students would need to use other methods than visual perception to justify their creation of a reflection in part II. The tracing paper served as a semiotic resource through which students could perform an operation such as folding and tracing to reflect the figure.

In part III, students were given an incomplete design (Figure 2c). The instructions for the problem required them to "come up with a way to reconstruct the design," assuming the design would have reflective symmetry. Part III, like part I, required students to produce a single figure with internal symmetry. Part III was different from parts I and II in that, although no line of reflection was provided, there were a finite number of lines that students could identify within the figure to produce a figure with reflective symmetry. We intended for students to draw a line segment to serve as the line of reflection as part of their operations for solving the problem. Additionally, we considered that in parts I and II of the lesson, students may likely have checked for equidistance between a pre-image and image from the line of reflection to verify the accuracy of their drawings. Based on this previous work, part III of the problem may have provoked 
students to use the process of locating a point equidistant from the line of reflection as an operation for completing the missing parts of the diagram.

Prior to distributing the pottery lesson, the teacher led a whole-class discussion with the students lasting approximately 6 minutes. In this discussion, the teacher asked students to consider examples of objects in their homes that displayed patterns. After students had an opportunity to discuss different examples of patterns, the teacher distributed the handout and had students look through the instructions for part I of the lesson as a class. When discussing the instructions, the teacher told students that the goal on the first page was to finish the design that had been started, and then to repeat that design to make a pattern. The teacher did not specify how students should reflect the images beyond the wording included in the handout. Each of the three problems in the lesson required students to create a pattern with reflective symmetry, which was taken to mean that students would reflect the figures provided in each problem.

\section{Data Collection}

Thirteen students participated in the study, and we divided students into four different groups (Table 1). We chose to place students in groups of 3-4 in an effort to foster discussion among the members of each group and comparisons of different solution strategies. We assigned students to groups prior to the session with input from the geometry teacher on which students were in the same class and would work well together. We positioned one video camera and audio recorder at each group to record students' conversations and gestures throughout the lesson. At the end of the session we collected all of the students' work, including the handouts we provided as well as any additional papers students used. For the purpose of analyzing data, the teacher occasionally asked students to enumerate copies of the figures in the order they had 
been drawn. The collection of video and audio records, as well as the artifacts students

produced, provided the data for our analysis of students' conceptions.

Table 1

Groups of Students Participating in the Pottery Lesson

\begin{tabular}{ll}
\hline Group & Students \\
\hline 1 & Joy (h), Frances (r), Sebastian (h) \\
2 & Alison (r), Nora (h), Andre (r), Markus (r) \\
3 & Trixy (r), Campbell (r), Solange (r) \\
4 & Dre (r), Morris (h), Amelia (r)
\end{tabular}

Note: We use h or $\mathrm{r}$ after students' names to indicate whether the student was enrolled in honors or, respectively, a regular section of geometry. Solange was in her first semester of geometry at the time of the study, while all other participants were in their second semester.

\section{Data Analysis}

We analyzed students' work on the pottery lesson according to the four components of the $\mathrm{cK} \not$ model. This technique is aligned with the qualitative approach of conceptions analysis, which seeks to describe how students use mathematical concepts in their work. The rationale for an analysis of students' conceptions through the $\mathrm{cK} \notin$ model is twofold. Research that focuses on students' conceptions moves beyond the evaluation of student work as correct or incorrect to provide insight into why students respond in particular ways to questions or prompts (Confrey, 1990). The use of the $\mathrm{cK} \notin$ model provides a way to see explicit evidence of students' understanding through the observable aspects of their work (Balacheff \& Gaudin, 2002). Thus, in employing the $\mathrm{cK} \varnothing$ framework, we draw upon research perspectives that prioritize understanding how students make sense of mathematics and that seek to find explicit evidence of this sense making in students' work. 
The first step of our analysis was to transcribe students' conversations during their work on the pottery lesson. Each author viewed the videos and prepared an initial transcript for one group of students. We met regularly to discuss our observations of students' work, and we began to enumerate the different semiotic resources and operations that students used for working on the problem. For example, during our conversations it became apparent that many of the students who used tracing paper solved the problem by rotating the tracing paper to make multiple copies of the design. Our conversations during the process of transcribing students' conversations provided the foundation for a more formal analysis of students' conceptions.

In the second phase of our analysis, each author viewed again the video for which he or she had produced the initial transcript. The authors provided qualitative descriptions of students' work according to the $\mathrm{cK} \phi$ framework. To guide this analysis, we created a viewing template to follow while watching the videos (Table 2). We examined the operations and semiotic resources that students used to solve each of the problems in the pottery lesson. Examining the work of one student at a time, we used the template to provide a short description of what the student was doing at various moments. Our unit of analysis was the individual student, even though students were working in small groups. As illustrated in Table 2 with the case of Sebastian, we included specific comments about the problem the student was solving and the operations he or she used. Because students did not always verbalize their actions, we relied upon evidence from the video and artifacts of students' work to verify our observations about the operations students performed. We also described the semiotic resources that students used to solve the problem, and, when possible, the control structure of the student's conception. We only identified a control structure when there was evidence making it explicit. 
Table 2

An Example of the First Stage of Analyzing Students' Conceptions, From the Work of Sebastian

\begin{tabular}{lll}
\hline Video Time Code & $0: 11: 30$ & $0: 12: 05$ \\
\hline Description & $\begin{array}{l}\text { When Sebastian first gets the } \\
\text { tracing paper, he uses the edge of } \\
\text { the paper as a straight edge. }\end{array}$ & $\begin{array}{l}\text { Sebastian places the tracing paper } \\
\text { over the given diagram, and he } \\
\text { begins to trace. }\end{array}$
\end{tabular}

\begin{tabular}{|c|c|c|}
\hline Problem Number & I. 1 & I.1 \\
\hline $\begin{array}{l}\text { Problem (student } \\
\text { interpretation) }\end{array}$ & $\begin{array}{l}\text { Reflect the left half of the diagram } \\
\text { over the vertical line. }\end{array}$ & $\begin{array}{l}\text { Reflect the left half of the diagram } \\
\text { over the vertical line. }\end{array}$ \\
\hline Operations & $\begin{array}{l}\text { 1. Adjust the tracing paper so that } \\
\text { the tracing paper is oriented } \\
\text { vertically and the worksheet is } \\
\text { oriented horizontally. } 2 \text {. Line up the } \\
\text { papers so that the tracing paper is } \\
\text { (almost) exactly perpendicular to } \\
\text { the worksheet and goes through a } \\
\text { vertex on the given diagram. } 3 \text {. } \\
\text { Extend a line segment from that } \\
\text { vertex, across the rest of the paper. }\end{array}$ & $\begin{array}{l}\text { 1. Line up the tracing paper on top of } \\
\text { the given worksheet. } 2 \text {. Trace over } \\
\text { the vertices of the given diagram. } 3 \text {. } \\
\text { Trace the line of reflection of the } \\
\text { given diagram. }\end{array}$ \\
\hline $\begin{array}{l}\text { Evidence } \\
\text { transcript }\end{array}$ & No evidence. & No evidence. \\
\hline $\begin{array}{l}\text { Evidence written } \\
\text { work }\end{array}$ & $\begin{array}{l}\text { Horizontal lines extending from } \\
\text { vertices on given diagram. }\end{array}$ & $\begin{array}{l}\text { Partial diagram drawn on tracing } \\
\text { paper. }\end{array}$ \\
\hline $\begin{array}{l}\text { Semiotic } \\
\text { resources }\end{array}$ & $\begin{array}{l}\text { 1. Diagram provided in the } \\
\text { worksheet. } 2 \text {. Line of symmetry, } \\
\text { which is provided as part of the } \\
\text { diagram. } 3 \text {. Tracing paper, which } \\
\text { serves as a straight edge. } 4 \text {. Line } \\
\text { segment extending from given } \\
\text { vertex, intersecting the line of } \\
\text { symmetry. }\end{array}$ & $\begin{array}{l}\text { 1. Diagram provided in the } \\
\text { worksheet. } 2 \text {. Line of symmetry, } \\
\text { which is provided as part of the } \\
\text { diagram. } 3 \text {. Tracing paper, which } \\
\text { serves as tracing paper. } 4 \text {. Partial } \\
\text { diagram drawn onto tracing paper. }\end{array}$ \\
\hline Control structure & No evidence. & No evidence. \\
\hline Evidence & 0:12:00 in video & No evidence. \\
\hline
\end{tabular}


We created a new column to describe a student's work each time the student's conception changed, as evidenced by a change in the problem, the operations, or the semiotic resources for solving the problem. For example, Sebastian initially began working on part I of the pottery lesson by using the tracing paper as a straightedge. He aligned the corner of the tracing paper with the edge of the worksheet to make it approximately perpendicular to the line of reflection and drew line segments from the vertices of the given figure across the line of reflection. After approximately 1 minute, Sebastian put the tracing paper on top of his worksheet and traced the vertices and the line of reflection of the given half-leaf diagram. Figure 3 includes the diagram that Sebastian produced on the tracing paper. The shift in the way Sebastian used the tracing paper reflected a change in his operations for solving the problem, and therefore initiated a new conception in the analysis.

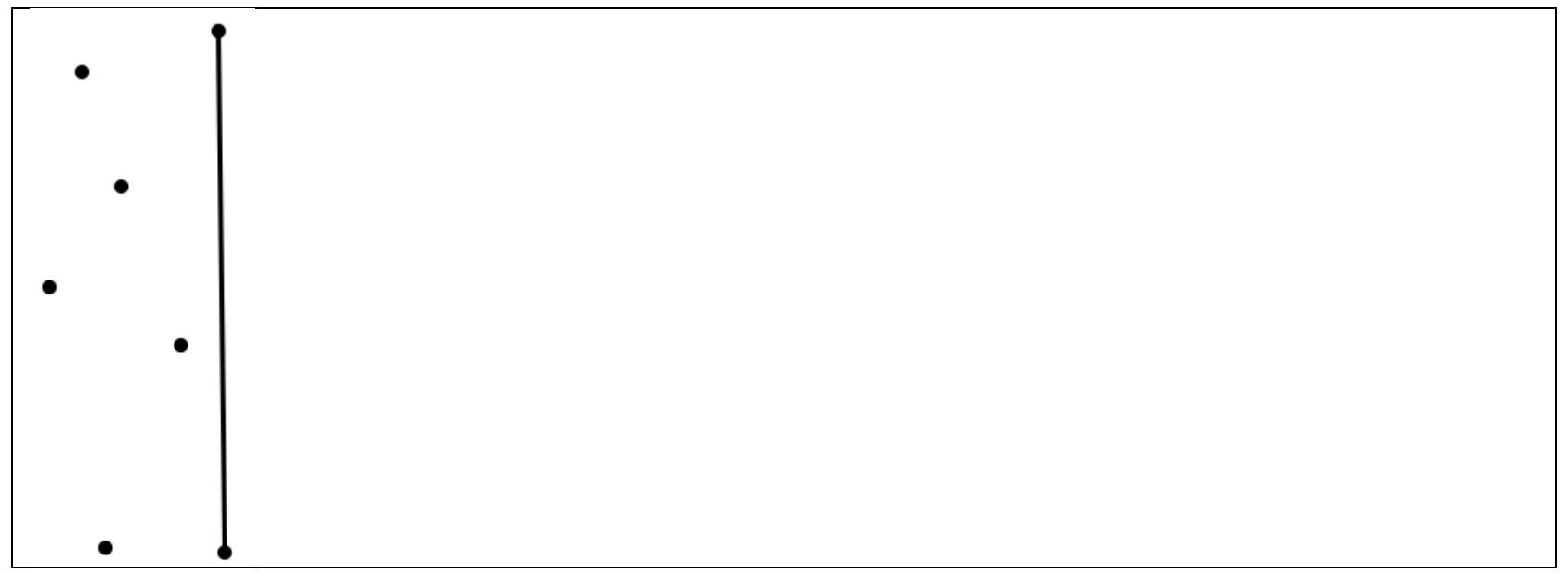

Figure 3. A reproduction of Sebastian's work after he traced the vertices and line of reflection in part I.

Based upon the qualitative descriptions of each student's work, the first author put together a list of problems, operations, semiotic resources, and control structures that appeared in students' work (see Appendix A for the complete list). The purpose of the list was to have a finite set of descriptors of students' work to check reliability of our analysis. Each author 
viewed his or her respective video a final time and coded students' work with the list of descriptors. The first author viewed and coded all four videos for comparison. As a result of this process there were two coders for three of the groups. To check our reliability, we computed the percentage of codes on which the second coder matched the primary coder. Our pairwise reliability ranged from $72 \%$ to $93 \%$. We grouped conceptions according to the common operations that students performed with the available semiotic resources.

Although our unit of analysis was the individual student, there were instances in which students' work was influenced by the work of the other members of their group. We allowed for these interactions because the goal of the study was to identify the different conceptions that would surface across a sequence of problems, and because of the benefit of having students make their operations and control structures explicit through conversation. Given the interactions between students, our findings regarding students' conceptions of reflection should not be taken to imply learning or progression of any individual student, but rather as a broad model for how students' work on a particular sequence of problems may progress.

\section{Results}

We identified five different conceptions of reflection in students' work. We present these conceptions in order, beginning with the most common conception we observed.

\section{Paper-Folding Conception}

Six of the students participating in the pottery lesson invoked a paper-folding conception of reflections. The paper-folding conception was characterized by students' use of the tracing paper to fold the paper and trace a reflection of a given diagram over the fold line. Table 3 outlines the paper-folding conception according to the components of the $\mathrm{cK} \phi$ model. Table 3 
The Paper-Folding Conception Described Through the cKф Model

\begin{tabular}{ll}
\hline Problem: & Complete the given diagram to create a figure with reflective symmetry. \\
$\left(P_{\text {Fold }}\right)$ & Or, create a strip pattern with reflective symmetry. \\
\hline Operations: & Trace a figure onto tracing paper. Fold the tracing paper along a line \\
$\left(R_{\text {Fold }}\right)$ & segment, which becomes the line of reflection. Trace an image of the \\
& figure reflected across the fold line of the paper, either by tracing each \\
& line segment or by tracing the vertices and connecting. Or, fold the \\
& worksheet on which the diagram is provided, and trace an image of the \\
& figure reflected across the fold line.
\end{tabular}

Semiotic Resources: Given diagram, as well as images produced by student. Tracing paper.

$\left(L_{\text {Fold }}\right) \quad$ Fold lines on paper. Straight edge.

Control Structure: $\quad$ When paper is folded, corresponding points should align. Corresponding

$\left(\Sigma_{\text {Fold }}\right) \quad$ points should be equidistant from the line of reflection.

Students using the paper-folding conception made extensive use of the tracing paper as a semiotic resource. Students used the paper-folding conception to solve two different types of problems. In parts I and III, students needed to reflect a given figure to produce reflective symmetry. In part I students could have used any edge of the given figure to identify a fold line, although as we expected, students most commonly selected the vertical line of the diagram as a line of reflection. In part III of the lesson, students needed to choose from three possible lines of reflection to complete the given figure. All students again used the vertical line of symmetry as the fold line in part III of the problem. 
In addition to completing a single reflection, students needed to create strip patterns that would display reflective symmetry in parts I and II of the lesson. In these instances, students could select any fold line to begin the work of reflecting a figure to make a strip pattern. Trixy's work on part II illustrates how students used a paper-folding conception to reflect copies of a figure (Figure 4). After tracing the given figure onto tracing paper, Trixy made a sequence of folds in her paper to reflect the figure multiple times. Students who used the paper folding conception invoked this conception consistently throughout their work on parts I-III of the lesson. In other words, changes to the figures in the second and third parts of the problem did not provoke students who performed paper folding to change their operations.

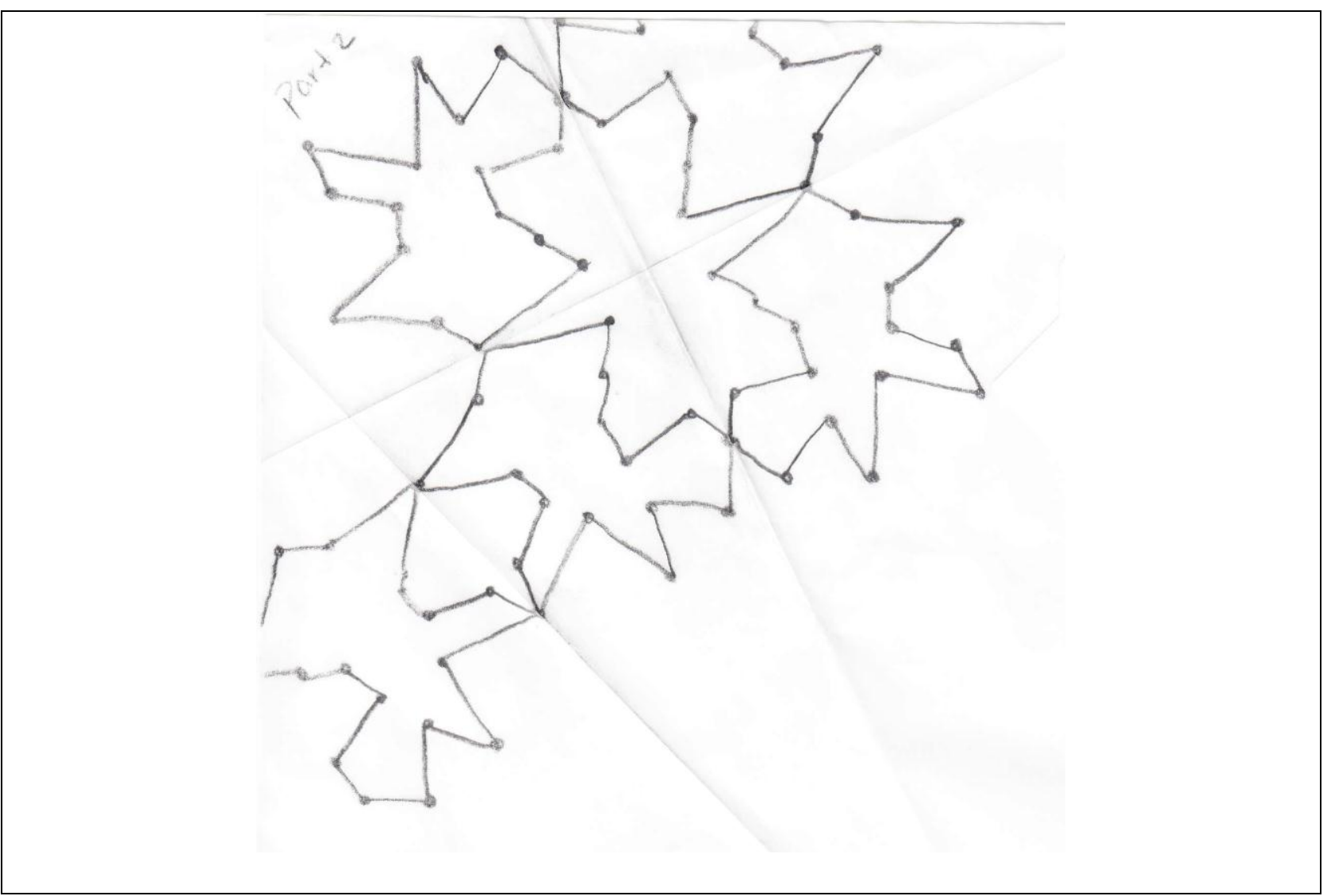

Figure 4. Evidence of the paper-folding conception from Trixy's work on Part II of the lesson. The lines of reflection were created when Trixy folded the tracing paper. 
Based upon our observations of students' work, there were two features of the paperfolding conception that made the perpendicular bisector salient in students' work. The first feature is that, through folding the paper, students made the lines of reflection explicit. This is evidenced through Trixy's work in Figure 4. The creases in Trixy's paper served as a semiotic resource for describing the relationship between a pre-image and its reflection.

In addition to the semiotic resource created by folding the paper, the control structure of the paper-folding conception allowed students to invoke the properties of a perpendicular bisector, even if these properties did not become explicit in their talk. Part II of the lesson included a question in which students needed to describe how they would determine whether the copies of the given figure were evenly spaced. The question was designed to provoke students to attend to the distances between copies of the figure and lines of reflection. When the teacher asked Joy to explain how she would measure the distances between the figures, Joy began to describe the relationship between a point and its reflection after the process of paper folding.

Joy: $\quad$ But like, after tracing this point you'd unfold it.

Teacher: Uh huh.

Joy: $\quad$ And then measure from each point.

Teacher: From?

Joy: Like, from this point to this point [indicating a point and its reflection]. And that's the distance between each figure.

Joy invoked the property that a point and its reflection would be equidistant from the line of reflection. Joy's process of checking pairs of points served as a control structure for the paper folding operation. The operation was validated by the property that a point and its reflection would be equidistant from a line of reflection. Although Joy did not make explicit the 
perpendicular nature of the line of reflection, she recognized that the line of reflection served as the bisector of the segment connecting a point to its reflection. Other students did not express this control structure verbally but instead checked their work by observing that corresponding points were aligned across the fold line.

\section{Flipping Conception}

Five of the students in our study used a flipping conception to complete one or more parts of the pottery lesson. Students used the tracing paper to invoke the flipping conception. Rather than folding the tracing paper to trace a given diagram, students traced multiple copies of the diagram on alternating sides of the tracing paper. Table 4 summarizes the flipping conception. Table 4

The Flipping Conception Described Through the $\mathrm{cK} \phi$ Model

Problem: $\quad$ Complete the given diagram to create a figure with reflective symmetry.

$\left(P_{\text {Flip }}\right) \quad$ Or, create a strip pattern with reflective symmetry.

Operations: $\quad$ Trace a figure onto tracing paper. Flip the tracing paper. Align a

$\left(R_{\text {Flip }}\right) \quad$ segment of the traced figure with its corresponding segment on the original figure. Trace another copy of the figure to create a reflection on the opposite side of the tracing paper. Or, place the flipped tracing paper under the worksheet and use it as a template for tracing a reflection on the original worksheet.

Semiotic Resources: Given diagram, as well as images produced by student. Tracing paper. $\left(L_{\text {Flip }}\right) \quad$ Straight edge.

Control structure: The figure and its image, when aligned after flipping the paper, should $\left(\Sigma_{\text {Flip }}\right) \quad$ look symmetric (inferred from student work). 
A result of the flipping conception is illustrated in Figure 5, which shows Dre's work on part II of the lesson. The leftmost image in Figure 5 is the first copy of the diagram that Dre drew, which he traced onto the tracing paper from the worksheet. After completing the first copy, Dre flipped his tracing paper and slid the tracing paper over to the right to align one vertex of his traced image with its corresponding point on the original diagram. Dre again traced the diagram from the worksheet and repeated the flipping process two more times. The alternating bold and faint segments in Figure 5 reflect that Dre's final product included copies of the original diagram on both sides of the tracing paper. The primary difference between the flipping conception and the paper-folding conception is that students using a flipping conception did not identify explicit lines of reflection.

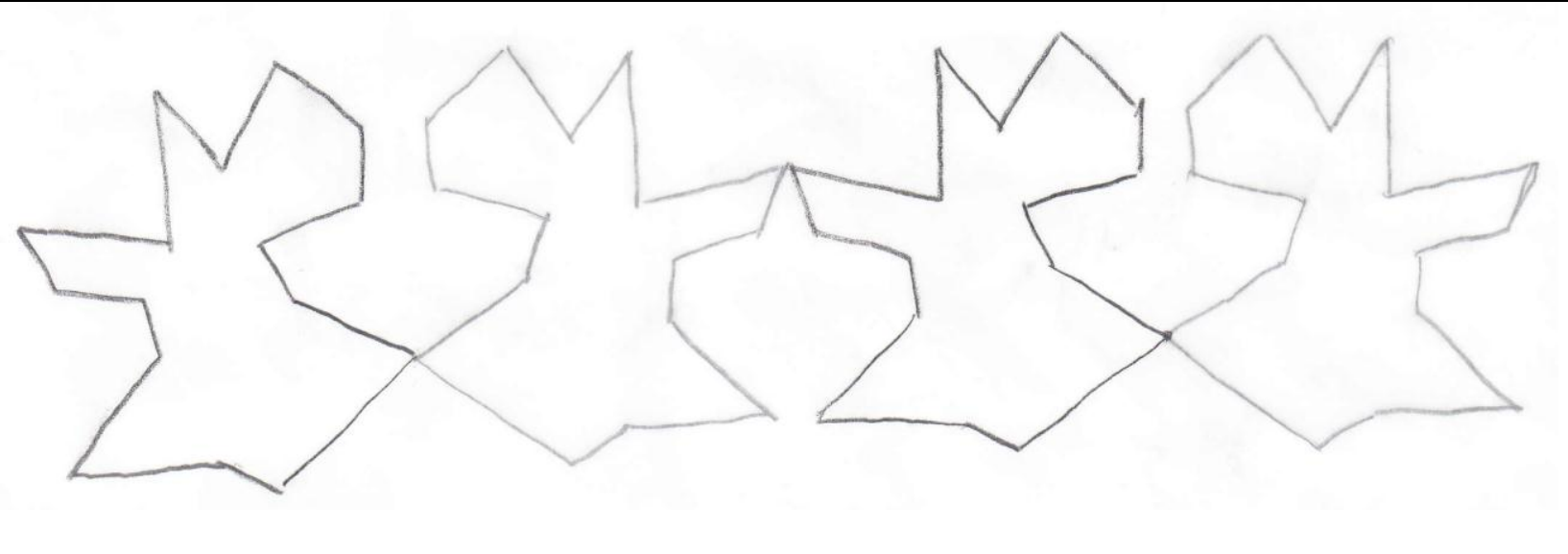

Figure 5. The result of Dre's use of the flipping conception to complete part II of the pottery lesson.

In contrast to the paper folding conception, students using the flipping conception did not produce a fold line or any other explicit representation of the line of reflection. Two of the students who used the flipping conception persisted in its use throughout the three parts of the lesson. Three students, who all worked together in a single group, shifted in their use of flipping 
to a rotating conception when they moved to part II of the lesson. We further discuss students' use of the rotating conception in the following section.

\section{Rotating Conception}

Four of the students in our study invoked the rotating conception to solve one or more of the problems included in the pottery lesson. We include this in our list of students' conceptions because of its relation to prior research identifying students' use of multiple different transformations to produce what they described as reflections (Hoyles \& Healy, 1997). The four students who invoked this conception seemed to interpret the problems in the lesson as calling for rotations of the original figure. Table 5 summarizes the rotating conception.

Table 5

The Rotating Conception Described Through the cKф Model

Problem: $\quad$ Complete the given diagram to create a figure with reflective symmetry.

$\left(P_{\text {Rotate }}\right) \quad$ Or, create a strip pattern.

Operations: $\quad$ Trace a given figure onto tracing paper. Rotate the tracing paper around

$\left(R_{\text {Rotate }}\right) \quad$ an implied center of rotation, and trace the figure again. Repeat the process to make multiple copies of the same figure.

Semiotic Resources: Given diagram, as well as images produced by student. Tracing paper.

$\left(L_{\text {Rotate }}\right) \quad$ Possibly, although not usually, a line that is described as a line of reflection. Straight edge.

Control Structure: $\quad$ Because the figure contains no internal symmetry, the strip pattern will $\left(\Sigma_{\text {Rotate }}\right) \quad$ not have reflective symmetry. Or, the problem calls for a creative design. Or, "flipping" the given diagram is equivalent to turning the diagram upside down. 
With the rotating conception, students produced images with some degree of rotational symmetry rather than reflective symmetry. Generally, students used either $90^{\circ}$ or $180^{\circ}$ rotations. Students used the tracing paper we provided, but instead of flipping or folding the tracing paper they rotated the paper to trace copies of the original diagram. Three of the students who used the rotating conception only invoked this conception on part II of the lesson, in which the provided figure contained no internal symmetry and the problem did not provide or suggest a line of reflection. Each of these three students had used paper folding on part I, and the change in the semiotic resources provided in the problem (specifically, the given figure) provoked a change in their operations for part II. Only one student used rotating for parts I and II of the lesson.

Figure 6 includes an example of the rotating conception from Andre's work on part II. The copy of the diagram labeled with a "1" was the first copy that Andre traced. To make the second copy of the diagram, Andre rotated his tracing paper, using the midpoint of one of the segments of the diagram as the center of rotation. Andre did not explicitly identify a center or number of degrees of rotation, but he rotated his paper approximately 180 degrees to make the second copy of the diagram. For the third copy, Andre implicitly used a point of rotation not on the traced figure, and he again rotated approximately 180 degrees. Andre referred to his rotations at various times throughout the lesson as "flipping" the original image. In the instructions for the lesson we did not instruct students to "flip." However, Andre seemed to interpret the problem as meaning that he needed to flip the given diagrams, and his operations for flipping included rotating the original figure. 


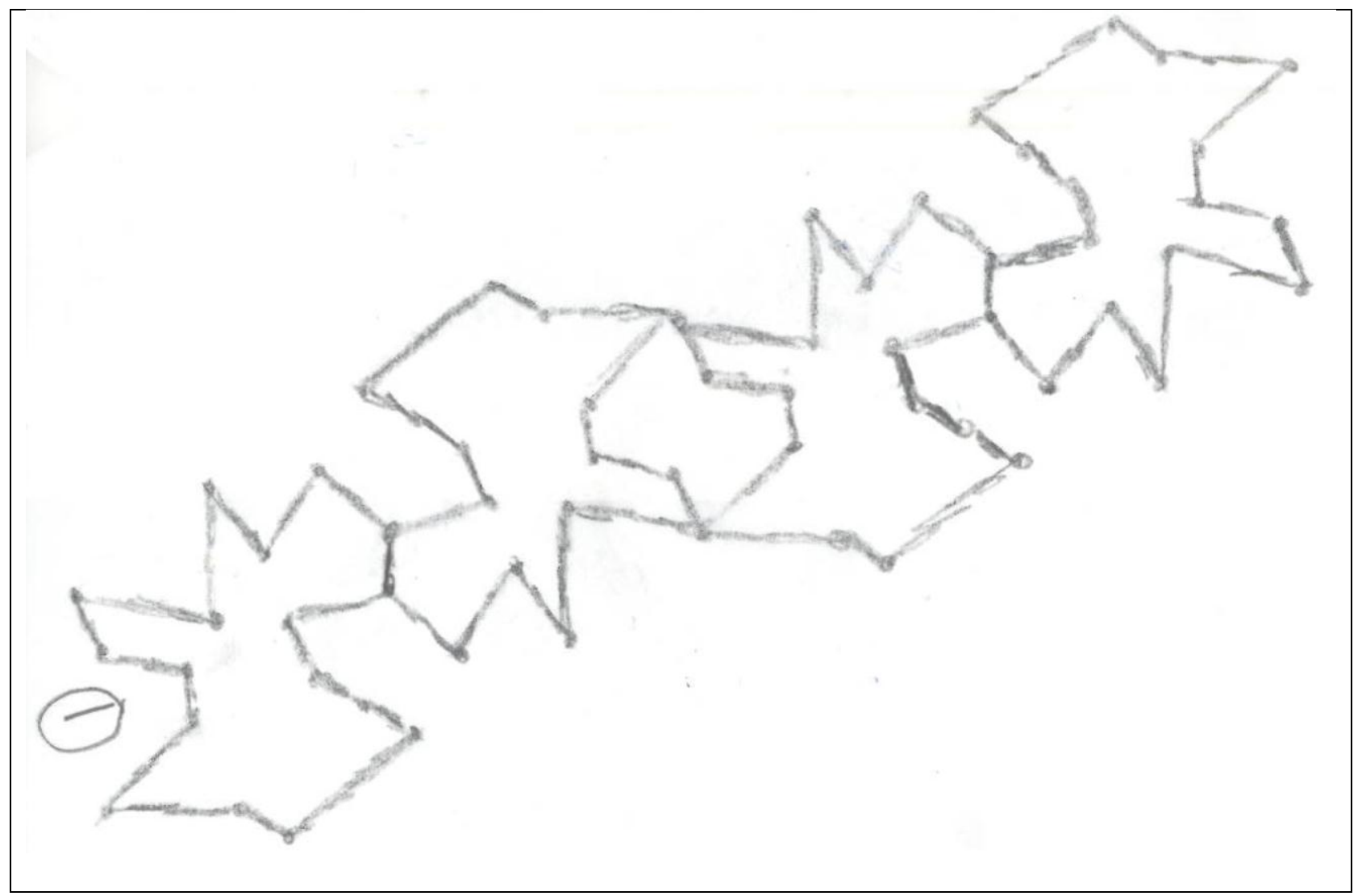

Figure 6. An example of the rotating conception in the work of Andre.

\section{Perpendicular Bisector Conception}

Only three students invoked the perpendicular bisector conception to complete any part of the pottery lesson. With the perpendicular bisector conception, students used the property that a line of reflection is the perpendicular bisector of a segment connecting a point to its reflected image. The perpendicular bisector conception of reflection can be described as in Table 6 .

Table 6

The Perpendicular Bisector Conception Described Through the $\mathrm{cK \phi}$ Model

Problem: $\quad$ Complete the given diagram to create a figure with reflective symmetry. $\left(P_{\text {Perp }}\right) \quad$ Or, create a strip pattern with reflective symmetry.

Operations: $\quad$ With a given diagram, measure the distance from given vertices to the 

$\left(R_{\text {Perp }}\right)$
(explicitly or implicitly defined) line of reflection. Align a straight edge
so that it is approximately perpendicular to the line of reflection. Place a
vertex on the opposite side, and equidistant from, the line of reflection as
the original vertex. Repeat these steps for each vertex in the given
diagram. Connect reflected vertices with line segments.
Semiotic Resources: Given diagram, as well as images produced by student. Line of
$\left(L_{\text {Perp }}\right) \quad$ reflection. Straight edge. Measuring device.
Control Structure: A line of reflection should be the perpendicular bisector of a segment
$\left(\Sigma_{\text {Perp }}\right) \quad$ connecting a vertex with its reflected image.

With the perpendicular bisector conception, students used the ruler as both a straightedge and a measuring device. Of the three students who invoked the perpendicular bisector conception, two of them used this conception only partly to work on part I of the lesson.

Sebastian, as we highlighted in Table 2, initially attempted to use perpendicular lines to reflect the vertices in the given half-leaf diagram in part I. However, Sebastian quickly abandoned this attempt and instead used paper folding to complete the problem. Another student in Group 1, Frances, also used perpendicular lines to complete the diagram in part I. After she reflected the half-leaf, Frances switched to paper folding to complete the strip pattern.

Nora was the only student who used the perpendicular bisector throughout the entire pottery lesson. Nora used the relationship between the line of reflection and the line segment connecting a point and its reflection to create multiple copies of the leaf diagram directly on her worksheet (Figure 7a). The figure labeled "1" in Figure 7a was the first reflection that Nora made, after drawing in a line of reflection to the left of the original diagram. Following this first 
reflection, Nora drew a second reflection of the original diagram, using the given vertical line as the line of reflection. Because Nora did not use a compass or protractor to create the reflected points, the line segments connecting points and their reflections are approximately perpendicular to the lines of reflection. On part III, Nora first identified the vertical line of reflection and then used perpendicular line segments to reflect the given points (Figure 7b). Nora's perpendicular bisector conception of reflection persisted throughout her work on the three parts of the lesson.

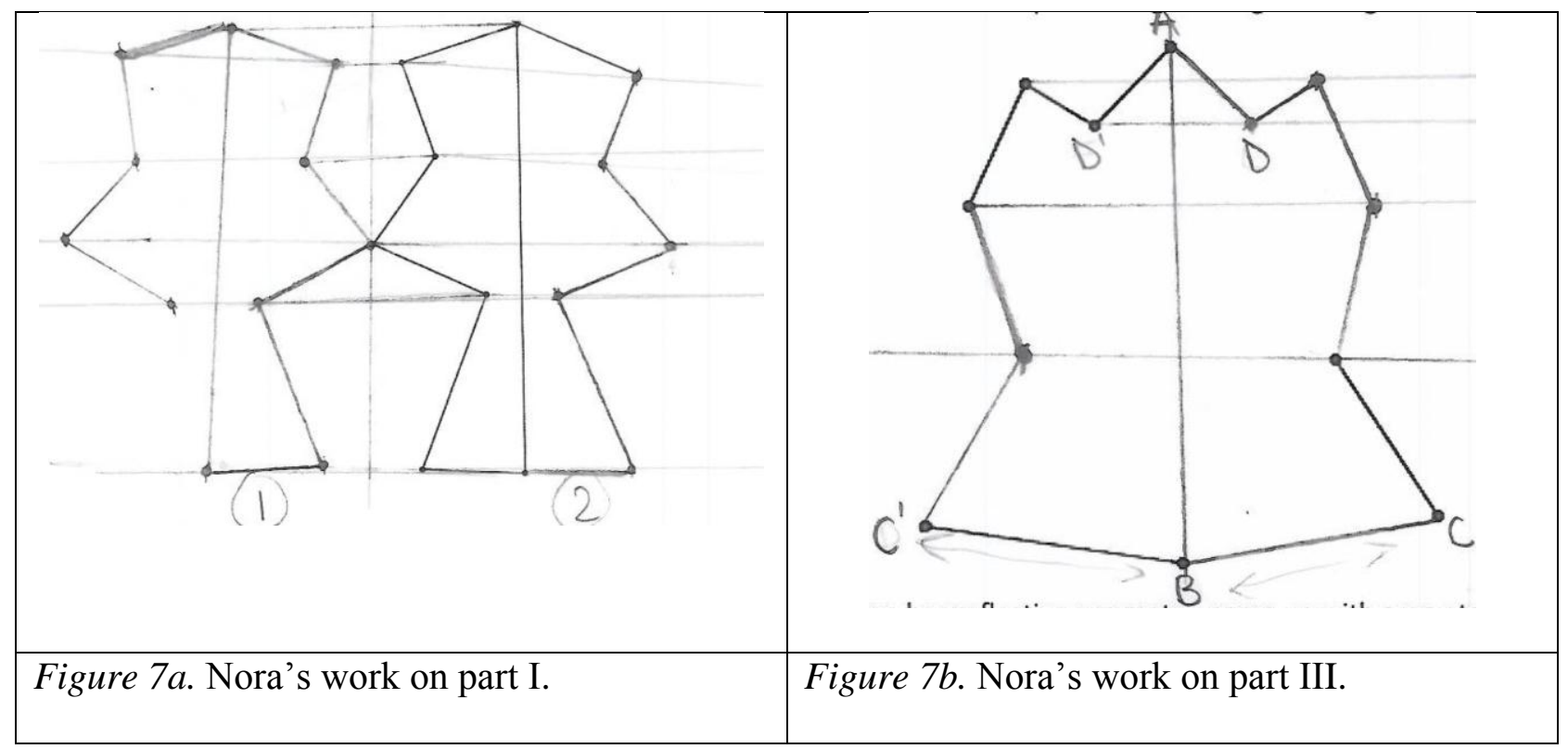

Figure 7. Evidence of the perpendicular bisector conception from the work of Nora in parts I and III of the lesson.

\section{Visual Conception}

The visual conception of reflections emerged in three students' work on part III of the lesson. With the visual conception, which is described in Table 7, students identified a line of symmetry and then drew line segments that were reflections of each of the given segments. Table 7

The Visual Conception Described Through the cKф Model 


$\left(P_{\text {Vis }}\right) \quad$ symmetry.

Operations:

Identify (either by drawing or describing) a vertical line of symmetry in

$\left(R_{V i s}\right)$

the given figure. Connect the vertex in the bottom center of the figure

with the vertex in the bottom right, to create a reflected segment. For

each of the rest of the given segments, draw a corresponding segment on

the other side of the line of reflection.

Semiotic Resources: Given diagram, either on the worksheet or traced onto the tracing paper.

$\left(L_{V i s}\right) \quad$ Line of reflection, either drawn or described. Straightedge.

Control Structure: $\quad$ Fold the tracing paper along the determined line of reflection to check

$\left(\Sigma_{\text {Vis }}\right) \quad$ whether the given segments and the drawn segments align.

The students in group 1 used the visual conception to work on part III. Frances seemed to be the first person in the group to identify a vertical line of symmetry in the diagram, and she began the process of drawing the reflected images of each line segment. Seemingly in response to hearing Frances describe her strategy, both Sebastian and Joy invoked the visual conception by identifying the vertical line of symmetry and reflecting individual line segments.

The primary difference in the way Sebastian and Joy invoked the visual conception compared to Frances was in their use of the semiotic resources and control structure. Both Joy and Sebastian traced the given diagram onto tracing paper before drawing the reflection. As they drew reflected line segments, Joy and Sebastian used paper folding as a measure of control to check whether they had drawn the reflections correctly. Both Joy and Sebastian noticed that their reflections did not align with the pre-image when folding the paper along the line of 
reflection. They abandoned the visual conception and returned to paper folding, using the line of reflection they had already identified.

\section{Discussion}

Our findings expand prior research describing students' understanding of reflections and suggest instructional implications in relation to the design of a sequence of problems and how to promote connections between reflection and perpendicular bisector. We organize our discussion around each of these points.

\section{Students' Conceptions of Reflection Through the Pottery Lesson}

Figure 8 summarizes students' conceptions of reflection in relation to the problems for which the different conceptions surfaced, as well as students' use of perpendicular bisector. The rotating conception required no explicit use of perpendicular bisector and, with one exception, surfaced only on part II of the lesson. The paper folding conception, which persisted throughout the three parts of the lesson, used perpendicular bisector as a control structure to validate the operations of folding paper and tracing. The visual and flipping conceptions illustrated potential for a teacher to encourage students' use of perpendicular bisector as a control structure, a point we discuss in more detail below. The perpendicular bisector conception uses the construction of a perpendicular bisector as an operation to reflect a figure. The arrows in Figure 8 illustrate shifts in students' use of particular conceptions. Specifically, students who invoked flipping, paper folding, and perpendicular bisector conceptions on part I generally used those respective conceptions throughout the lesson. The dotted arrows indicate that some students shifted from flipping to rotating on part II of the lesson, while some students shifted to the visual conception from paper folding on part III. Finally, there were two students who initially invoked a perpendicular bisector conception but then shifted to paper folding for the duration of the lesson. 


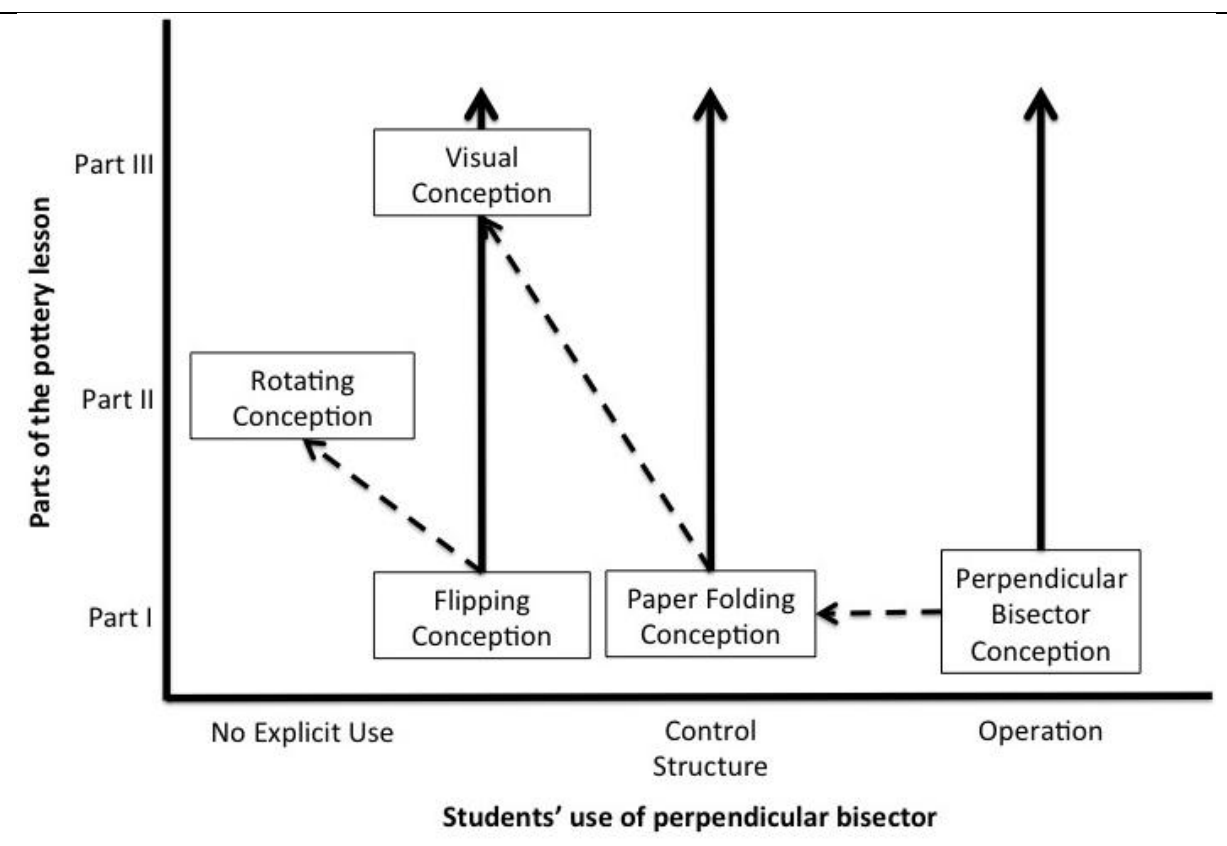

Figure 8. Organization of students' conceptions according to the parts of the problem in which each conception surfaced (vertical) and students' use of perpendicular bisector (horizontal). Dotted arrows indicate evidence of students moving between one conception and another.

Both the visual and flipping conceptions recall the notion that students have many informal experiences with symmetry in which they have not needed to formalize aspects of transformations (Jagoda \& Swoboda, 2011). In particular, students often have a multitude of experiences working with horizontal and vertical lines of symmetry (Sinclair, Pimm, \& Skelin, 2014). By providing figures that suggested vertical lines of symmetry in parts I and III, students were able to validate their work based upon their prior knowledge of what a reflection should look like. In contrast, the rotating conception relied upon the assumption that the product of one's work would not include reflective symmetry. ${ }^{3}$ Students invoking the rotating conception

\footnotetext{
${ }^{3}$ One important consideration is that geometry diagrams in textbooks often provide any points or segments necessary for solving a problem, particularly in the case of proof exercises (Dimmel \& Herbst, 2016; Herbst, 2004). It is possible that students did not see part II as requiring reflection because we did not provide an explicit line of reflection. However, we also did not provide any center or degree of rotation to guide students towards rotating the figure. In the absence of any auxiliary components in the problem, some students perceived parts of the pottery lesson as requiring rotations to produce symmetry.
} 
conflated reflection with rotation. There is evidence that such conflations between rotations and reflections may persist, ranging from middle grades students to pre-service teachers (Hoyles \& Healy, 1997; Son, 2006). When comparing the rotating conception to the visual and flipping conceptions, the importance of control structure for determining a conception is evident. In cases where students knew that the resulting pattern of their work should contain reflective symmetry, they could draw upon their knowledge of reflections to check the validity of their solutions. The assumption that the resulting pattern would contain no reflective symmetry validated the operation of rotating, which produced non-reflective patterns.

The paper folding and perpendicular bisector conceptions can be contrasted in terms of how each drew upon the use of perpendicular bisector. With the perpendicular bisector conception, students used the definition of a line of reflection as the perpendicular bisector of the segment connecting a point to its reflection. As in prior research (e.g., Hollebrands, 2003), students who used the perpendicular bisector conception displayed understanding that a reflection could be defined through the relationship between the line of reflection and a segment connecting a point and its reflection. Students in the study had previously studied perpendicular bisector in their geometry class, although only three students initially invoked this conception for part I of the lesson. Students who used the paper folding conception, which was much more common, used properties of reflection in relation to perpendicular bisector as a control structure. While these two conceptions were unique from the other three, because they both made explicit use of the perpendicular bisector, they differed from one another in whether the control structure served as an operation, or as a measure of control. 


\section{Instructional Implications}

There are reasons to create opportunities for students to use perpendicular bisector both as an operation and as a control structure when creating reflections. Students in geometry should be able to develop a definition of a reflection as a transformation using perpendicular lines and segments (NGAC, 2010). Although students can generally state and describe the properties of a perpendicular bisector (Hollebrands, 2003; Marrades \& Gutiérrez, 2000), they do not always use these properties for establishing relationships between geometric objects (Marrades \& Gutiérrez, 2000; Miyakawa, 2004). Students may benefit from work on tasks in which the most efficient way to create a reflection is through the operation of creating or constructing line segments perpendicular to the line of reflection. By asking students to complete the given figure in part III of the pottery lesson, we aimed for students to identify ways to reflect points, thus constructing perpendicular lines in the process. Students may benefit from tasks like part III in which there are non-vertical and non-horizontal lines of reflection to expand their perception of how reflections look. To support students' use of the perpendicular bisector as an operation in creating reflections, a teacher may need to make the relationship between a line of reflection and perpendicular bisector explicit, in particular with regards to how students had used these objects on earlier parts of the lesson. We also recognize that a teacher may be able to remove tracing paper from the milieu, or to only introduce it for the purpose of a control structure, in order to promote students' use of perpendicular bisector on a task such as part III of the pottery lesson.

We can also consider the value of perpendicular bisector as a control structure in students' work. A primary goal of instruction is for students to learn mathematics with understanding, meaning that students establish a network of interrelated ideas and knowledge of how those ideas fit together (Hiebert \& Carpenter, 1992). The ability to use perpendicular 
bisector in different ways, in response to different types of tasks, is an indicator of students' flexible use of the concept. Students like Frances and Sebastian seemed to have flexible understanding of the relationship between perpendicular bisector and reflective symmetry. Both students initially began constructing perpendicular bisectors to reflect the figure in part I of the lesson, but they quickly recognized the relative efficiency of using paper folding to complete the three problems. Even as they used paper folding, however, both Sebastian and Frances validated their work by checking that pre-images and images were equidistant from their lines of reflection. There are examples in research of how students may shift their activities so that an action, which at one time served as an operation of a conception, at another time can serve as a measure of control (e.g., González \& Herbst, 2009). Such a shift indicates flexibility in students' use of mathematical objects and relationships for understanding particular concepts.

The use of perpendicular bisector as a control structure can also be introduced as a resource for students who may rely entirely on informal experiences to motivate the work of producing reflections. Although neither flipping nor the visual conception made the line of reflection explicit, each suggests an opportunity for formalizing a control structure through the use of the perpendicular bisector. From the perspective of teaching, it may serve multiple purposes to suggest the use of an explicit line of reflection at this stage. Teachers can support students' metacognitive processes by pushing students to make the motivation and validation of their operations explicit (Schoenfeld, 1985). Students can benefit from developing strategies for self-monitoring to determine whether their mathematical solutions make sense (Carpenter et al., 1999). Using the line of reflection to check the validity of a reflection created through either a visual or flipping conception also serves a specific purpose relative to the mathematical content of the task. By doing so, a teacher can provoke conversation about how the line of reflection 
serves as a measure of control, and specifically that it serves as the perpendicular bisector of the segment connecting a pre-image and its reflection.

In all but one case, students who used the rotating conception only did so on part II of the pottery lesson, after using flipping on part I. It is important to recognize the difference in semiotic resources included in part II of the lesson, namely that the problem did not imply any particular line of reflection. Because of this, both the selection and sequencing of tasks should be carefully considered from the perspective of fostering students' connections between reflection and perpendicular bisector. Given that students' conflation of reflections and rotations can persist beyond the secondary grades (Son, 2006), a task like part II of the pottery lesson is useful to elicit and overcome potential sources of confusion. Instruction should provide opportunities for students to encounter concepts not only with, but also against, their previous conceptions (Herbst, 2005). For a teacher to challenge a student's conception of reflection, the student should have alternative operations, semiotic resources, and measures of control to draw upon. A teacher who has introduced the use of the line of reflection as a control structure on a previous task could reintroduce that line of reflection as a semiotic resource to challenge students' assumptions about the possibility of reflecting a non-symmetric figure.

\section{Limitations and Directions for Future Research}

We recognize in light of the $\mathrm{cK} \phi$ framework that our findings regarding students' conceptions are intertwined with the tasks and semiotic resources we provided. Students chose to use tracing paper from the semiotic resources available for the lesson. In other settings, for example when students work on the computer rather than with paper and pencil (e.g., Hoyles \& Healy, 1997; Hollebrands, 2003), it is less likely that a paper folding conception would be the most common conception surfacing in students' work. Similarly, the tasks included in the 
pottery lesson all required students to reflect points and figures. Tasks related to conjecture and proof are likely to elicit other conceptions that are beyond the scope of this study (e.g., Miyakawa, 2004). It is important to keep in mind that a conception is not entirely a characteristic of a learner, but rather a characteristic of the learner-milieu interaction (Balacheff, 2013; Balacheff \& Gaudin, 2010). Future work in the area of students' understanding of reflections and perpendicular bisector should examine the ways in which students' conceptions shift or evolve through the introduction of alternative tasks or semiotic resources.

We note that our findings about students' conceptions, and the ways in which perpendicular bisector was made explicit in their work, should be considered in light of the setting of the study. Given that students participated in the study during an after-school focus group session, they did not necessarily adhere to the typical didactical contract (Brousseau, 1997; Herbst, 2003) through which teachers and students act according to an implicit set of norms. Additionally, students' work during the pottery lesson was likely informed by their prior knowledge of perpendicular bisector and transformations from their geometry class. We found the after-school setting to offer the benefit that students were not bound by standard curricular expectations, and therefore we could explore the range of students' thinking. Future research can extend the findings of this study by examining more deeply how an instructional sequence in a typical classroom may be able to draw upon the conceptions illustrated in Figure 8 for the purpose of promoting student learning within a lesson or unit.

\section{Conclusion}

Current research on students' thinking and learning suggests documenting students' ideas to support teachers' anticipation of student thinking (e.g., Simon, 1995; Sztajn, Confrey, Wilson, \& Edgington, 2012). Describing students' conceptions related to specific concepts can be an 
important resource in teaching and teacher education. These descriptions can provide a basis for teachers to foster learning with understanding by examining the connections through which students can build networks of ideas (Hiebert \& Carpenter, 1992). In elementary mathematics education, for example, research on the different ways students come to understand integers (e.g., Bishop et al., 2014) has helped teachers to tailor instruction so that it is more connected to how students learn. Our study adds to a body of literature on students' understanding of reflections and reflective symmetry (e.g., Hollebrands, 2003; Mhlolo \& Schäfer, 2014; Miyakawa, 2004) that can provide a basis for teachers to build upon aspects of student understanding that may not otherwise be made explicit.

In geometry, perpendicular bisector is one example of a concept with many connections to other geometric objects and relationships (Herbst, 2005; Marrades \& Gutiérrez, 2000; Zbiek \& Connor, 2006). We designed a sequence of problems that would leverage connections between perpendicular bisector and reflection to consider how an emphasis on geometric transformations can be used as a basis for fostering students' learning. Although we found that students' use of particular conceptions generally persisted, even as the semiotic resources provided in the presentation of the problems changed, we noticed opportunities in students' work to elicit the use of perpendicular bisector either in the role of an operation or as a measure of control.

The pottery lesson was designed to build upon students' prior knowledge. In particular, we expect that students typically draw upon knowledge from school mathematics, as well as informal mathematical practices and their experiences in the world (González, DeJarnette, \& Deal, 2014). With our sequence of tasks and our provision of semiotic resources, we sought to provide students multiple entry points through which they could engage in the pottery lesson. We recognize that students' multiple sources of prior knowledge become reflected through their 
mathematical work. By providing a careful characterization of students' conceptions, we attempt to privilege students' prior knowledge while at the same time identifying opportunities for growth in student thinking. 


\section{References}

Balacheff, N. (2013). cKф, A model to reason on learners' conceptions. In M. V. Martinez \& A. C. Superfine (Eds.), Proceedings of the $35^{\text {th }}$ annual meeting of the North American Chapter of the International Group for the Psychology of Mathematics Education (pp. $2-$ 15). Chicago, IL: University of Illinois at Chicago.

Balacheff, N., \& Gaudin, N. (2002). Students' conceptions: An introduction to a formal characterization. Cahier Leibniz, 65, 1-21.

Balacheff, N., \& Gaudin, N. (2003). Conceptual framework. In S. Soury-Lavergne (Ed.), Baghera assessment project: Designing a hybrid and emergent educational society. Les Cahiers du Laboratoire Leibniz, 81 (pp. 3-22). Grenoble, France: Laboratoire LeibnizIMAG.

Balacheff, N., \& Gaudin, N. (2010). Modeling students' conceptions: The case of function. In F. Hitt, D. Holton, \& P. W. Thompson (Eds.), CBMS Issues in Mathematics Education: Vol. 16. Research in collegiate mathematics education (pp. 183-211). Providence, RI: American Mathematical Society.

Bishop, J. P., Lamb, L. L., Philipp, R. A., Whitacre, I., Schappelle, B. P., \& Lewis, M. L. (2014). Obstacles and affordances for integer reasoning: An analysis of children's thinking and the history of mathematics. Journal for Research in Mathematics Education, 45(1), 1961. doi:10.5951/jresematheduc.45.1.0019

Brousseau, G. (1997). Theory of didactical situations in mathematics: Didactique des mathematiques 1970-1990 (N. Balacheff, M. Cooper, R. Sutherland, \& V. Warfield, Eds. And Trans.). Dordrecht, the Netherlands: Kluwer. 
Brown, A. L. (1992). Design experiments: Theoretical and methodological challenges in creating complex interventions in classroom settings. Journal of the Learning Sciences, 2(2), 141178. doi:10.1207/s15327809j1s0202_2

Carpenter, T. P., Fennema, E., Franke, M. L., Levi, L., \& Empson, S. B. (1999). Children's mathematics: Cognitively guided instruction. Portsmouth, NH: Heinemann.

Carter, J. A., Cuevas, G. J., Day, R., Malloy, C., \& Cummins, J. (2014). Glencoe Geometry. Columbus, OH: McGraw-Hill.

Cobb, P., Confrey, J., diSessa, A., Lehrer, R., \& Schauble, L. (2003). Design experiments in educational research. Educational Researcher, 32(1), 9-13. doi:10.3102/0013189X032001009

Collins, A. (1992). Toward a design of science education. In E. Scanlon \& T. O’Shea (Eds.), New directions in educational technology (pp. 15-22). New York, NY: Springer.

DeJarnette, A. F., \& González, G. (2016a). Geometry students' arguments about a 1-point perspective drawing. Manuscript submitted for publication.

DeJarnette, A. F., \& González, G. (2016b). Thematic analysis of students' talk while solving a real-world problem in geometry. Manuscript accepted to Linguistics and Education.

DeJarnette, A. F., Rosado Lausell, S. L., \& González, G. (2015). Shadow puppets: Exploring a context for similarity and dilations. The Mathematics Teacher, 109(1), 20-27. doi:10.5951/mathteacher.109.1.0020

Dimmel, J. K., \& Herbst, P. G. (2015). The semiotic structure of geometry diagrams: How textbook diagrams convey meaning. Journal for Research in Mathematics Education, 46(2), 147-195. doi:10.5951/jresematheduc.46.2.0147 
Donovan, M. S., \& Bransford, J. D. (Eds.). (2005). How students learn: Mathematics in the classroom. Washington, DC: National Academies Press.

Freudenthal, H. (1991). Revisiting mathematics education: China lectures. Dordrecht, Netherlands: Kluwer.

González, G., DeJarnette, A. F., \& Deal, J. T. (2014). Assessing and using students’ prior knowledge in problem-based instruction. New England Mathematics Journal, 46(1), 3849.

González, G., \& Herbst, P. (2009). Students' conceptions of congruency through the use of dynamic geometry software. International Journal of Computers for Mathematical Learning, 14(2), 153-182. doi:10.1007/s10758-009-9152-z

Herbel-Eisenmann, B. A., \& Otten, S. (2011). Mapping mathematics in classroom discourse. Journal for Research in Mathematics Education, 42(5), 451-485. doi:10.5951/jresematheduc.42.5.0451

Herbst, P. (2003). Using novel tasks in teaching mathematics: Three tensions affecting the work of the teacher. American Educational Research Journal, 40(1), 197-238. doi:10.3102/00028312040001197

Herbst, P. (2004). Interactions with diagrams and the making of reasoned conjectures in geometry. ZDM: The International Journal on Mathematics Education, 36(5), 129-139. doi:10.1007/BF02655665

Herbst, P. (2005). Knowing about “equal area"' while proving a claim about equal areas. Recherches en Didactique des Mathématiques, 25(1), 11-56. 
Hiebert, J., \& Carpenter, T. P. (1992). Learning and teaching with understanding. In D. A. Grouws (Ed.), Handbook of research on mathematics teaching and learning (pp. 65-97). New York, NY: Macmillan.

Hiebert, J., Gallimore, R., Garnier, H., Givvin, K. B., Hollingsworth, H., Jacobs, J., Chui, A., M.Y., Wearne, D., Smith, M., Kersting, N., Manaster, A., Tseng, E., Etterbeek, W., Manaster, C., Gonzalez, P., \& Stigler, J. W. (2003). Teaching mathematics in seven countries: Results from the TIMSS 1999 video study (NCES 2003-013). Washington, DC: U.S. Department of Education, National Center for Education Statistics.

Hollebrands, K. F. (2003). High school students' understandings of geometric transformations in the context of a technological environment. Journal of Mathematical Behavior, 22(1), 55-72. doi:10.1016/S0732-3123(03)00004-X

Hoyles, C., \& Healy, L. (1997). Unfolding meanings for reflective symmetry. International Journal of Computers for Mathematical Learning, 2(1), 27-59. doi:10.1023/A:1009721414546

Jagoda, E., \& Swoboda, E. (2011). Static and dynamic approach to forming the concept of rotation. In M. Pytlak, E. Swoboda, \& T. Rowland (Eds.), Proceedings of the Seventh Congress of the European Society for Research in Mathematics Education (pp. 558-567). Rzeszów, Poland: University of Rzeszów.

Lemke, J. L. (1990). Talking science: Language, learning, and values. Westport, CT: Ablex. Marrades, R., \& Gutiérrez, A. (2000). Proofs produced by secondary school students learning geometry in a dynamic computer environment. Educational Studies in Mathematics, 44(1-2), 87-125. doi: 10.1023/A:1012785106627 
Martínez-Planell, R., Gonzalez, A. C., DiCristina, G., \& Acevedo, V. (2012). Students’ conception of infinite series. Educational Studies in Mathematics, 81(2), 235-249. doi:10.1007/s10649-012-9401-2

Mesa, V. (2004). Characterizing practices associated with functions in middle school textbooks: An empirical approach. Educational Studies in Mathematics, 56(2-3), 255-286. doi:10.1023/B:EDUC.0000040409.63571.56

Mhlolo, M. K., \& Schäfer, M. (2014). Potential gaps during the transition from the embodied through the symbolic to formal worlds of reflective symmetry. African Journal of Research in Mathematics, Science and Technology Education, 18(2), 125-138. doi:10.1080/10288457.2014.925269

Miyakawa, T. (2004). Reflective symmetry in constructions and proving. In Proceedings of the $28^{\text {th }}$ Conference of the International Group for the Psychology of Mathematics Education: Vol. 3 (pp. 337-344). Bergen, Norway.

National Council of Teachers of Mathematics. (2000). Principles and Standards for School Mathematics. Reston, VA: Author.

National Council of Teachers of Mathematics. (2009). Focus in high school mathematics: Reasoning and sense making. Reston, VA: Author.

National Governors Association Center for Best Practices \& Council of Chief State School Officers. (2010). Common core state standards for mathematics. Washington DC: Author. Retrieved from http://www.corestandards.org/assets/CCSSI_Math\%20Standards.pdf 
Ng, O.-L, \& Sinclair, N. (2015). Young children reasoning about symmetry in a dynamic geometry environment. ZDM Mathematics Education. Advance online publication. doi:10.1007/s11858-014-0660-5

Páez Murrillo, R. E., \& Vivier, L. (2013). Teachers' conceptions of tangent line. The Journal of Mathematical Behavior, 32(2), 209-229. doi:10.1016/j.jmathb.2013.02.005

Perham, A. E., \& Perham, F. L. (2011). Voronoi diagrams and spring rain. Mathematics Teacher, 105(2), 126-132. doi:10.5951/mathteacher.105.2.0126

Poehl, T. T. (2012). Delivered tomorrow: Plane and truck geometry. Mathematics Teacher, 105(9), 702-706. doi:10.5951/mathteacher.105.9.0702

Schoenfeld, A. (1985). Mathematical problem solving. Orlando, FL: Academic Press.

Schoenfeld, A. (1988). When good teaching leads to bad results: The disasters of "well-taught" mathematics courses. Educational Psychologist, 23(2), 145-166. doi:10.1207/s15326985ep2302_5

Sherin, M. G. (2001). Developing a professional vision of classroom events. In T. Wood, B S. Nelson, \& J. Warfield (Eds.), Beyond classical pedagogy: Teaching elementary school mathematics (pp. 75-93). Hillsdale, NJ: Lawrence Erlbaum.

Simon, M. (1995). Reconstructing mathematics pedagogy from a constructivist perspective. Journal for Research in Mathematics Education, 26(2), 114-145. doi:10.2307/749205

Sinclair, N., Pimm, D., \& Skelin, M. (2012). Developing essential understanding of geometry: Grades 6-8. Reston, VA: National Council of Teachers of Mathematics.

Son, J.-W. (2006). Investigating preservice teachers' understanding and strategies on a student's errors of reflective symmetry. In J. Novotná, H. Moraová, M. Krátká, \& N. Stehlíková (Eds.), Proceedings of the $30^{\text {th }}$ conference of the International Group for the Psychology 
of Mathematics Education, Vol. 5 (pp. 145-152). Prague: PME.

Son, J.-W., \& Sinclair, N. (2010). How preservice teachers interpret and respond to student geometric errors. School Science and Mathematics, 110(1), 31-46. doi:10.1111/j.19498594.2009.00005.x

Sztajn, P., Confrey, J., Wilson, P. H., \& Edgington, C. (2012). Learning trajectory based instruction: Toward a theory of teaching. Educational Researcher, 41(5), 147-156. doi:10.3102/0013189X12442801

Vergnaud, G. (1981). A classification of cognitive tasks and operations of through involved in addition and subtraction problems. In J. P. Carpenter, J. M. Moser, \& T. A. Romberg (Eds.), Addition and subtraction: A cognitive perspective (pp. 39-59). Hillsdale, NJ: Lawrence Erlbaum.

Vergnaud, G. (1998). A comprehensive theory of representation for mathematics education. Journal of Mathematical Behavior, 17(2), 167-181. doi:10.1016/S0364-0213(99)80057-3

Vergnaud, G. (2009). The theory of conceptual fields. Human Development, 52(2), 83-94. doi:10.1159/000202727

Zbiek, R. M., \& Conner, A. (2006). Beyond motivation: Exploring mathematical modeling as a context for deepening students' understandings of curricular mathematics. Educational Studies in Mathematics 63(1), 89-112. doi:10.1007/s10649-005-9002-4 
Appendix A:

Components of Students' Conceptions According to the $\mathrm{cK} \phi$ Model

\section{Problems $(P)$}

1. Copy the given figure.

2. Describe a step-by-step process for creating a pattern with reflective symmetry.

3. Determine how to complete the figure in Part III.

4. Determine whether the figures are evenly spaced around the vase.

5. Find a line of symmetry in the diagram in Part III.

6. Finish the given figure so that it has reflective symmetry. [Part III]

7. Finish the given figure. [Part III]

8. Make a creative, unique, or abstract pattern or design.

9. Make a pattern with reflective symmetry.

10. Make a strip with multiple copies of the design with symmetry.

11. Make a strip with multiple copies of the design.

12. Reflect the given half-leaf diagram over the horizontal line.

13. Reflect the given half-leaf diagram over the vertical line.

\section{Operations $(R)$}

1. Approximate a copy of the given figure by re-drawing without measuring sides or angles.

2. Connect open vertices of figure in Part III.

3. Connect vertices.

4. Count number of copies of design.

5. Estimate where to place a point along a line segment extending from a given vertex through a 
line of symmetry.

6. Extend line segments from given vertices across a line of reflection.

7. Extend the vertical line segment of the leaf figure to extend the line of reflection.

8. Flip the tracing paper.

9. Fold paper along a line segment of the given figure.

10. Fold the paper along a line of symmetry.

11. Identify a line of reflection in Part III.

12. Line up a straight edge so that it's perpendicular with the line of reflection.

13. Make multiple copies of the figure facing various directions.

14. Measure the distance from a given vertex to the line of reflection.

15. Measure the distance from the line of reflection to mark a reflection of the vertex.

16. Place the tracing paper (with a diagram drawn on) underneath the worksheet to trace.

17. Rearrange line segments to make a closed figure.

18. Repeat previous steps.

19. Rotate the tracing paper 180 degrees.

20. Rotate the tracing paper 90 degrees.

21. Rotate the tracing paper.

22. Trace a copy of the figure onto the tracing paper.

23. Trace a reflection of the figure on the tracing paper.

24. Trace a reflection of the vertices onto the tracing paper.

25. Trace the given figure onto tracing paper.

26. Trace the given vertices onto the tracing paper.

27. Translate tracing paper. 
Note: Operations R24 and R3 were originally combined as a single operation (trace a reflection of the vertices onto the tracing paper and connect vertices), as were R26 and R3 (trace the given vertices onto the tracing paper and connect vertices). After our second round of analysis we separated the codes to account for instances in which students used one, but not the other, operation.

\section{Semiotic Resources $(L)$}

1. Diagram created by student

2. Fold line on paper

3. Given diagram in Part II

4. Given diagram in Part III

5. Given half-leaf diagram in Part I

6. ID card as a straight edge

7. Paper as a straight edge

8. Paper as a tool for making 90-degree angle

9. Ruler as a measuring device

10. Ruler as a straight edge

11. Space on the worksheet

12. Tracing paper writing on both sides

13. Tracing paper writing on one side 
1. Ask another student.

2. Ask the instructor.

3. Corresponding points should be equidistant from line of reflection.

4. Invoke a theorem.

5. Look at another student's worksheet.

6. The design should look unique.

7. The diagram does not look right.

8. The diagram looks right. 